\title{
Dynamic Analysis of Gear and Rack Transmission System
}

\author{
Xiao Yanjun, He Lihu, Zhu Jiayu and Xiao Yanchun*
}

Hebei University of Technology, Tianjin, 300130, China

\begin{abstract}
This paper firstly established a three-dimensional modal of gear and rack transmission system. By using finite element analysis software the model is analyzed and the first six natural frequencies of the gear and rack transmission system are acquired. According to the natural frequencies, actual working speed can be adjusted to avoid resonance. In light of the modal analysis, the transient dynamic finite element model of the gear and rack transmission system is established for the transient dynamic analysis. According to the equivalent stress contour of the gear and rack in contact progress at various times and based on transient dynamic analysis, contact strength and bending strength of the gear are verified and the maximum equivalent stress position is found, providing a theoretical basis for the optimization of the gear and rack.
\end{abstract}

Keywords: Contact strength, gear and rack, modal analysis, transient dynamic analysis.

\section{INTRODUCTION}

With the advantages of high transmission efficiency, strong carrying capacity and the stability of the transmission ratio, the gear and rack transmission system is commonly used in force and motion transmission in the mechanical system. The reliability and stability of the gear and rack directly influences the regular operation of the mechanical equipment $[1,2]$.

The traditional measures are usually used to calculate the contact stress and bending stress which can only help obtain the value of a single point of time on one contact surface. Moreover, it has the following problems: complicated calculation process, time-consuming, inexactitude of the calculated result. The structure static analysis is a systematic verification process in steady load. However, when the load changes with time, the dynamics and statics characteristics which the system represented are different $[3,4]$. The three-dimensional model of the gear and rack transmission system was built by the 3D design software UG, and the model analysis was conducted on the gear and rack transmission system by the software of ANSYS Workbench in order to identify the natural frequencies of the gear and rack transmission system. On this basis, transient dynamic analysis of the gear and rack system is carried out to get equivalent stress distribution at different times in the gear and rack meshing contact process and the strength of contact and bending strength of the gear and rack is examined.

\section{GEAR AND RACK SYSTEM DYNAMIC MODEL}

Two gears can constitute a gear transmission system without considering the auxiliary element of the gear and the elastic deformation of the gear itself. The vibration model is shown in Fig. (1) [5].

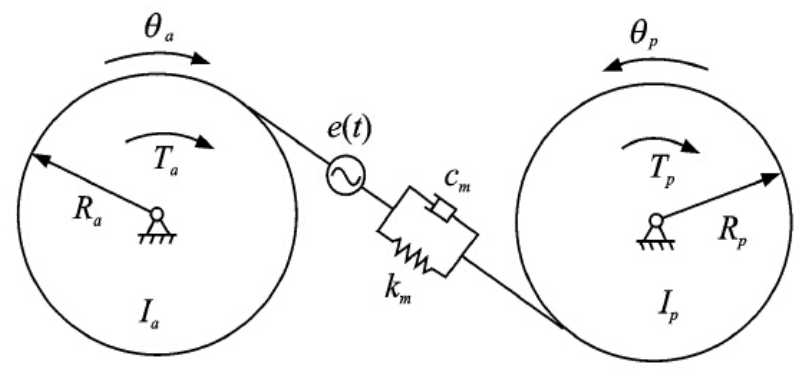

Fig. (1). Gear meshing dynamics model.

From Fig. (1), we can see the vibration analysis model of gear pair is as follows:

$$
\begin{aligned}
& I_{\mathrm{a}} \ddot{\theta}_{a}+c_{m}\left(R_{a} \dot{\theta}_{a}-R_{p} \dot{\theta}_{p}\right) R_{a}-c_{1} \dot{e}_{1} R_{a}-c_{2} \dot{e}_{2} R_{a}+ \\
& k_{m}\left(R_{a} \theta_{a}-R_{p} \theta_{p}\right) R_{a}-k_{1} e_{1} R_{a}-k_{2} e_{2} R_{a}=T_{a} \\
& I_{p} \ddot{\theta}_{p}+c_{m}\left(R_{p} \dot{\theta}_{p}-R_{a} \dot{\theta}_{a}\right) R_{p}-c_{1} \dot{e}_{1} R_{p}-c_{2} \dot{e}_{2} R_{p}+ \\
& k_{m}\left(R_{p} \theta_{p}-R_{a} \theta_{a}\right) R_{p}-k_{1} e_{1} R_{p}-k_{2} e_{2} R_{p}=-T_{p}
\end{aligned}
$$

In the formulas:

$I$ - Moment of inertia of the gear;

$\theta$-Vibration displacement of the gear;

$R$-Pitch circle radius of the gear;

$T$-Load acting on the gear;

$k_{1}, k_{2}$-Composite stiffness of gear teeth;

$c_{1}, c_{2}$-Meshing damping coefficient of gear teeth;

$e$-Meshing error of gear teeth;

$c_{m}$-Meshing damping of the gear;

$k_{m}$-Meshing stiffness of the gear. 
The rack can be viewed as a gear, but its radius is infinite. Therefore, the vibration analysis model of gear pairs applies to gear and rack transmission system in this paper.

The contact stress of gear and rack transmission derived by the Hertz theory can be expressed as:

$\sigma_{H}=\sqrt{\frac{F}{\pi L} \frac{\frac{1}{R_{r e d}}}{\frac{1-v_{1}^{2}}{E_{1}}+\frac{1-v_{2}^{2}}{E_{2}}}}=Z_{H} Z_{E} Z_{\varepsilon} \sqrt{\frac{F_{t}}{b d_{1}} \cdot \frac{u \pm 1}{u} K_{A} K_{v} K_{H \alpha} K_{\beta}}$

In the formula:

$K_{A}$ - Coefficient of working condition;

$K_{V}$-Coefficient of dynamic load;

$K_{\mathrm{Ha}}$-Transverse load distribution coefficient of the contact strength;

$K_{\beta}$-Distribution coefficient of tooth lead load;

$Z_{H}-$ Coefficient of node cell;

$Z_{E}-$ Coefficient of elasticity;

$Z_{\tau}$ - coefficient of overlap ratio.

As the calculation method of the contact stress of gear and rack is derived by the deformation and coefficient correction based on Hertz formula. Therefore, the calculated contact stress and the actual contact stress have certain amount of deviation. The finite element method can solve the problem.

\section{MODAL ANALYSIS}

Using ANSYS workbench for the dynamic analysis of the gear and rack system, modal analysis of the gear and rack system must be done in the first place. The modal analysis belongs to the dynamic analysis and its main purpose is to find out the natural frequency of the gear and rack system and to provide the data for the transient dynamics analysis of gear and rack system. By comparing the natural frequency and meshing frequency of the gear and rack system, the speed of the gear is, whether it's reasonable, can be determined. Regulating the gear speed can prevent its natural frequency.

Finite Element Modeling. In this paper, the basic parameters of the gear are: modulus $=4$, the number of teeth is 25 and pressure angle is $20^{\circ}$. The $3 \mathrm{D}$ model of the gear and rack transmission system was built by the 3D design software UG. The gear and rack assembly model in ANSYS is obtained by importing into the ANSYS Workbench the $\mathrm{x}_{-} \mathrm{t}$ file format of the $3 \mathrm{D}$ model. The material of gear and rack is $40 \mathrm{Cr}$ with a density $7820 \mathrm{~kg} / \mathrm{m}^{3}$, elastic modulus 206GPa, and Poisson's ratio of 0.28 .

In order to adequately reflect the variation of gear and rack contact result, the gear and rack system requires intensive meshing. The gear and rack are sliced in this paper. Dense meshing is done only on the gear contact area. The local mesh refinement can reduce the number of skewed mesh. Better mesh can make the results more accurate. In the gear and rack meshing region, the element size is set $1 \mathrm{~mm}$, and the unimportant regional element size is set $20 \mathrm{~mm}$. There are
31418 units and 154405 nodes. The finite element model is shown in Fig. (2).

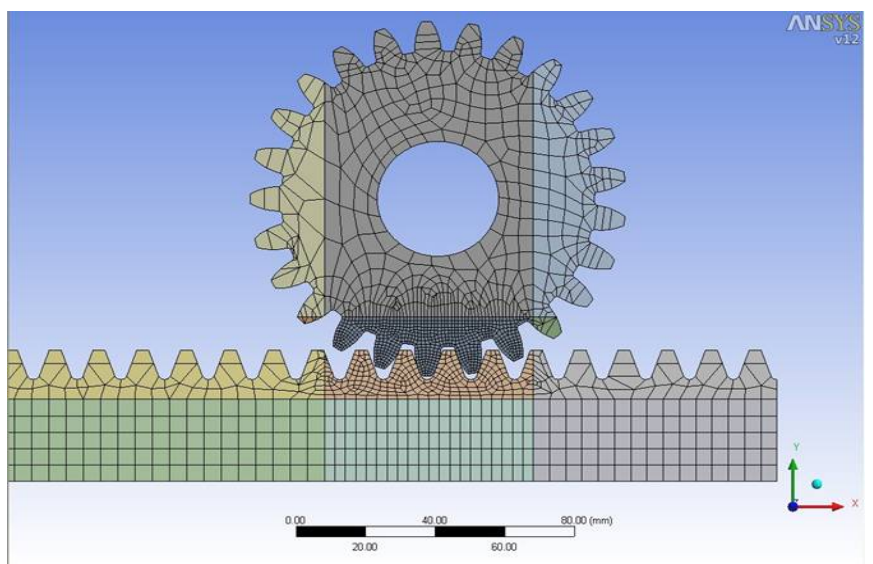

Fig. (2). The finite element model of the gear and rack system.

Imposing Constraints. The main purpose of the modal analysis is to find out the natural frequency of the gear and rack system. So there is no need to apply load to the model. Only a degree of freedom constraint is needed. In order to match the actual working conditions, it must be ensured that the gear only rotates around the $\mathrm{Z}$ axis and the rack only translates along the $\mathrm{X}$ direction. A revolute-ground constraint on the gear and a translational-ground constraint on the front surface of the rack, need to be added in Connections. Then, a cylindrical support on the gear and a displacement on the bottom surface of the rack in modal are added. According to the actual condition of the rack, add forced displacement to the rack in the $\mathrm{X}, \mathrm{Y}, \mathrm{Z}$ directions. Constraint conditions is shown in Fig. (3).

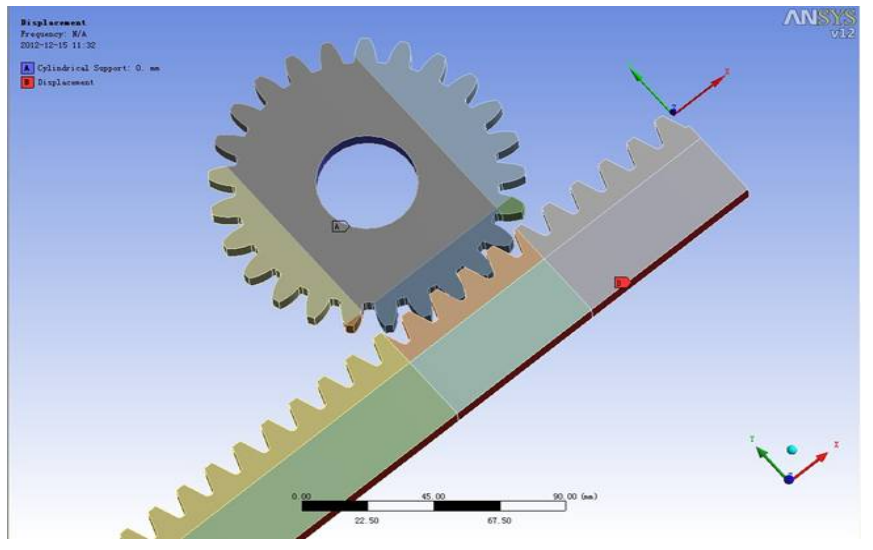

Fig. (3). Schematic diagram of constraint.

Modal Analysis Results and Discussion. Modal analysis of the system, generally, needs to compute a few lower-order frequencies. Because higher modes have little effect on the dynamic characteristics of the structure and usually only the low order natural frequency may cause the system resonance $[6,7]$. The first six order natural frequency is obtained by the post-processor, as shown in Table 1.

According to the definition of the gear meshing frequency, gear meshing frequency equals to the rotational frequency multiplied by the number of teeth. When the number of gear teeth is 25 , the gear meshing frequency is $16 \mathrm{~Hz}$ at the speed of $0.65 \mathrm{r} / \mathrm{s}$ by calculation, which is far 
less than the lowest natural frequency. Therefore, it is likely to avoid the resonance frequency. In order to improve production efficiency, the speed of gear can be improved, which can have different external excitation conditions in different production efficiency.

Table 1. The first six order natural frequency of the gear and rack system.

\begin{tabular}{|c|c|c|}
\hline $\begin{array}{c}\text { Mode } \\
\text { Number }\end{array}$ & Frequency/HZ & $\begin{array}{c}\text { The Maximum } \\
\text { Displacement/mm }\end{array}$ \\
\hline \hline 1 & 464.07 & 9.128 \\
\hline 2 & 1979.8 & 12.312 \\
\hline 3 & 3800.8 & 12.541 \\
\hline 4 & 5676.6 & 15.163 \\
\hline 5 & 7348.4 & 24.496 \\
\hline 6 & 8452 & 21.072 \\
\hline
\end{tabular}

\section{TRANSIENT DYNAMIC ANALYSIS}

Gear and rack system is commonly used as a component in mechanical device, so its strength check has practical implications. Typically the contact stress, bending stress of gear and rack are computed by traditional methods. However, the conventional formula to calculate the contact stress in the gear is only on one certain point of time and on one contact surface. The pitch circle circumferential force acting on the top gear can be used to calculate the bending stress. The contact stress calculated by transient dynamics analysis in this paper is a range of values which describes the contact stress values at different times and in different contact position of the gear and rack. At different point of time, the influence of the bending of gear and rack is different due to the size of the meshing force and the acting position. This transient dynamics description method can describe the gear and rack meshing process more realistically $[8,9]$.

Transient Dynamic Finite Element Model. As discussed above, through modal analysis of gear and rack, intrinsic characteristics of the system are obtained. On the basis of the above, the transient response analysis is performed in this part by adding the transient dynamic module (Transient Structural).

Transient Analysis Settings. Set the transient response time step $\mathrm{t}=1 / 20$ and $\mathrm{f}=0.0001 \mathrm{~Hz}$ to get transient response. Turn on automatic time-step effect and set the maximum time step to $1.0 \mathrm{e} \sim 004 \mathrm{~s}$, the minimum time step is $1.0 \mathrm{e} \sim 005 \mathrm{~s}$, the initial time step is $1.0 \mathrm{e}-005 \mathrm{~s}$. When loading the speed of gear, the project is divided in two steps, first, the acceleration phase, then the uniform phase. The deadline of acceleration phase time step is $1.0 \mathrm{e}-002 \mathrm{~s}$, and the deadline of uniform phase time step is $0.15 \mathrm{~s}$.

Load Settings. First, set the gear speed. Here the steady speed of gear is set to $0.65 \mathrm{r} / \mathrm{s}$. The default units in ANSYS workbench is $\mathrm{rad} / \mathrm{s}$ and the speed of gear can be transformed into $4.08 \mathrm{rad} / \mathrm{s}$, as shown in Fig. (4). Second, set the rack load. In this paper the gear drives the rack to transmit power, so it needs to apply horizontal load along the moving direction of the rack. Set the load to $400 \mathrm{~N}$. A cylindrical support needs to be added to the gear and displacement on the bottom surface of the rack is added in Transient. According to the actual condition of the rack, add forced displacement to the rack in the $\mathrm{X}, \mathrm{Y}, \mathrm{Z}$ directions. Finally add the options of the results in Solution and the transient analysis setting is completed.

\begin{tabular}{|c|c|c|c|}
\hline \multicolumn{4}{|c|}{ Tabular Data } \\
\hline & Steps & Time [s] & $\sqrt{\checkmark}$ Rotational Velocity [ $\mathrm{rad} / \mathrm{s}]$ \\
\hline 1 & 1 & 0. & 0. \\
\hline 2 & 1 & 1. $e^{-002}$ & 4.08 \\
\hline 3 & 2 & 0.15 & $=4.08$ \\
\hline * & & & \\
\hline
\end{tabular}

Fig. (4). Gear load settings.

Transient Dynamic Analysis Results and Discussion. The transient dynamics analysis is done on the gear and rack meshing process. The equivalent stress contour of the gear and rack in the meshing process is shown in Fig. (5). Four graphs of (a) (b) (c) (d) represent meshing equivalent stress contours at the moments of $0.03 \mathrm{~s}, 0.05 \mathrm{~s}, 0.08 \mathrm{~s}$, $0.12 \mathrm{~s}$.

Fig. (6) shows the equivalent stress contour of gear respectively in $0.03 \mathrm{~s}, 0.05 \mathrm{~s}, 0.08 \mathrm{~s}, 0.12 \mathrm{~s}$.

Fig. (7) shows the equivalent stress contour of rack respectively in $0.03 \mathrm{~s}, 0.05 \mathrm{~s}, 0.08 \mathrm{~s}, 0.12 \mathrm{~s}$.

Figs. $(6,7)$ are the meshing separate diagrams of gear and rack in Fig. (5). As seen from Fig. (6), the maximum equivalent stress of the gear was at the addendum, followed by tooth surface and root.

From Fig. (5) we can see that the maximum equivalent stress of gear is $741.59 \mathrm{MPa}$, less than the tensile strength $860 \mathrm{Mpa}$. It can be seen from Fig. (6) that the maximum equivalent stress of the gear and rack occurs in the gear and rack out-meshing contact point, and only in this point. The reason is that there is local high stress in the addendum line. Local high stress can cause premature failure of the addendum, leading to the gear failure. This is why the gear tooth is patched on the top to avoid the condition of local high stress in engineering.

In addition, Fig. (7) shows that the equivalent stress of the rack changes with time. The maximum stress of the rack is at the dedendum, followed by tooth surface meshing line. From Fig. (7) we can clearly see that the meshing line changes over time. The maximum stress of rack is $702.31 \mathrm{MPa}$, less than the bending strength $815.28 \mathrm{MPa}$ of the rack, which can meet the design requirements.

\section{CONCLUSION}

The three-dimensional model of the gear and rack transmission system is built by UG and the modal analysis was conducted on the gear and rack transmission system by the software of ANSYS workbench. In light of that, the transient dynamic analysis of the gear and rack system is carried out and the analysis shows that: 
(a) $\mathrm{T}=0.03 \mathrm{~s}$ Gear and rack meshing stress contour

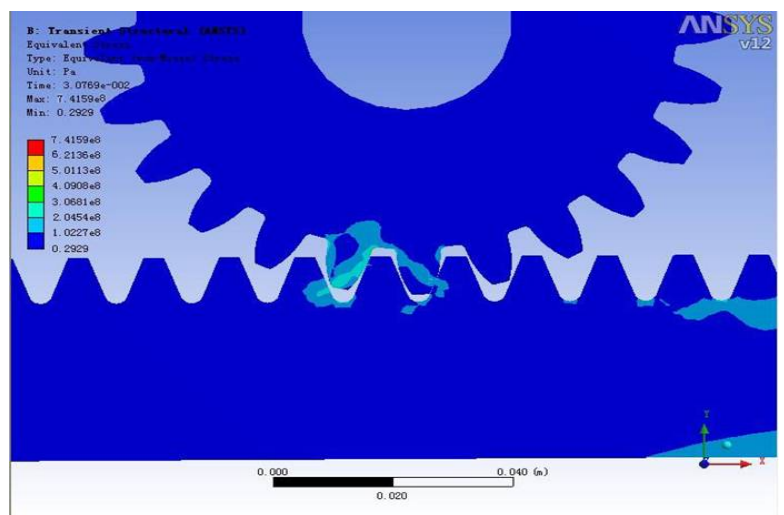

(b) $\mathrm{T}=0.05 \mathrm{~s}$ Gear and rack meshing stress contour

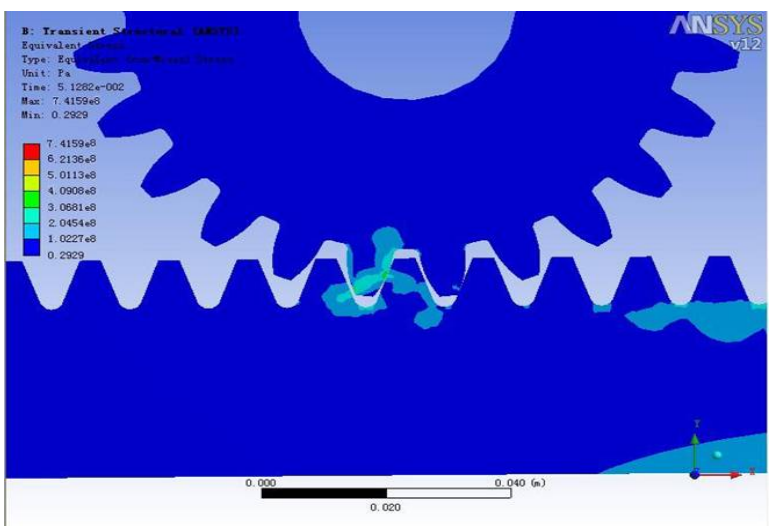

(c) $\mathrm{T}=0.08 \mathrm{~s}$ Gear and rack meshing stress contour

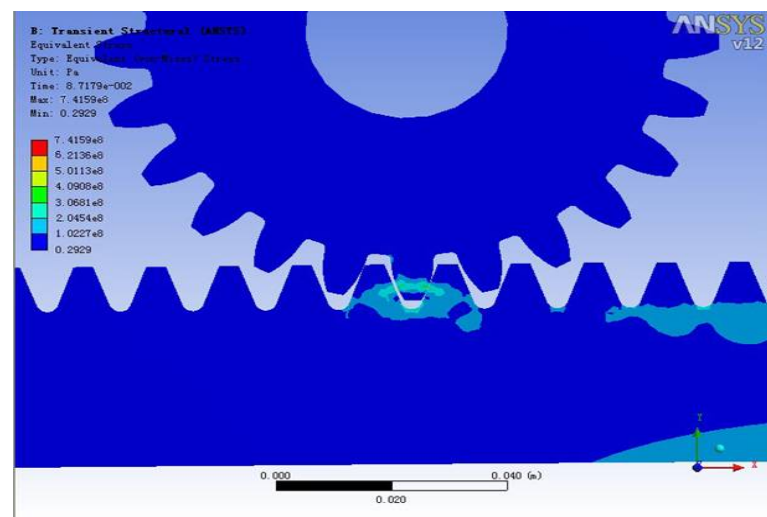

(d) $\mathrm{T}=0.12 \mathrm{~s}$ Gear and rack meshing stress contour

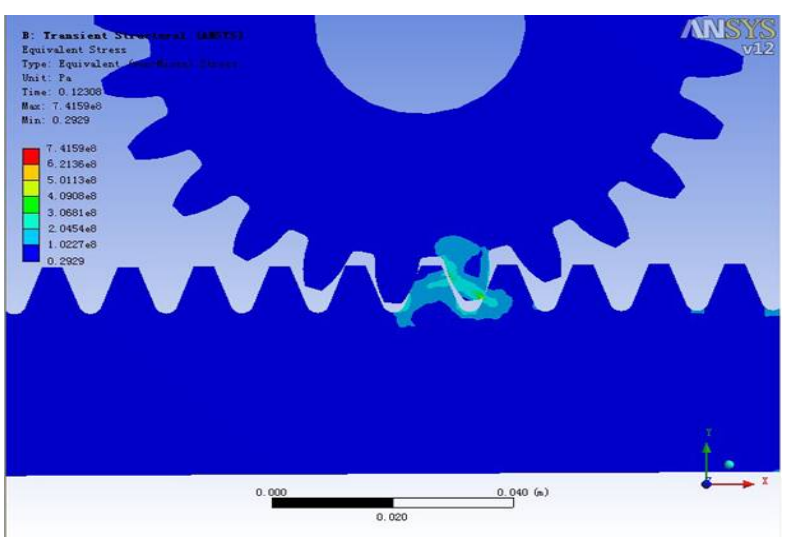

Fig. (5) Gear and rack meshing stress contour. (a) $\mathrm{T}=0.03 \mathrm{~s}$ Gear stress contour

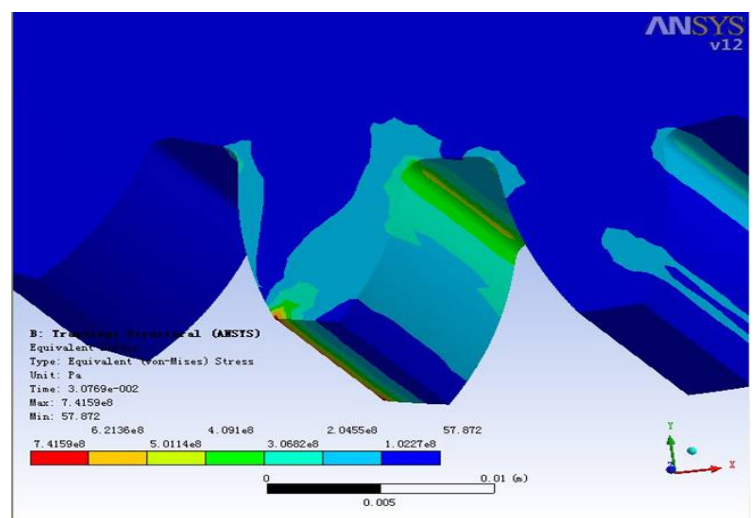

(b) $\mathrm{T}=0.05 \mathrm{~s}$ Gear stress contour

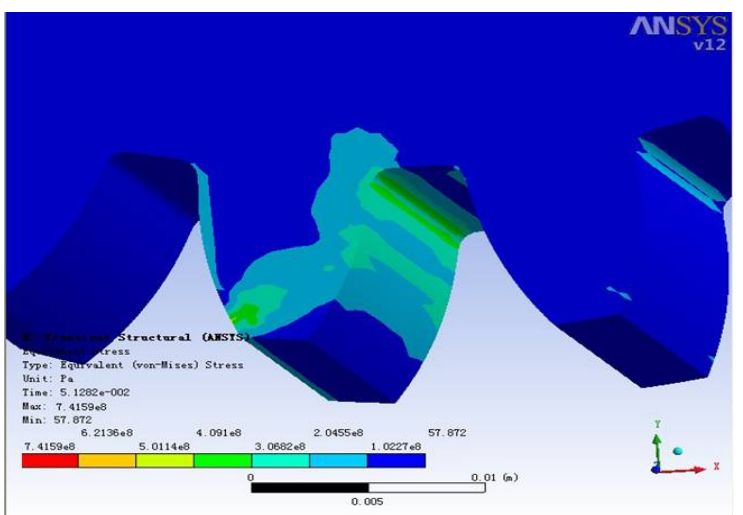

(c) $\mathrm{T}=0.08 \mathrm{~s}$ Gear stress contour

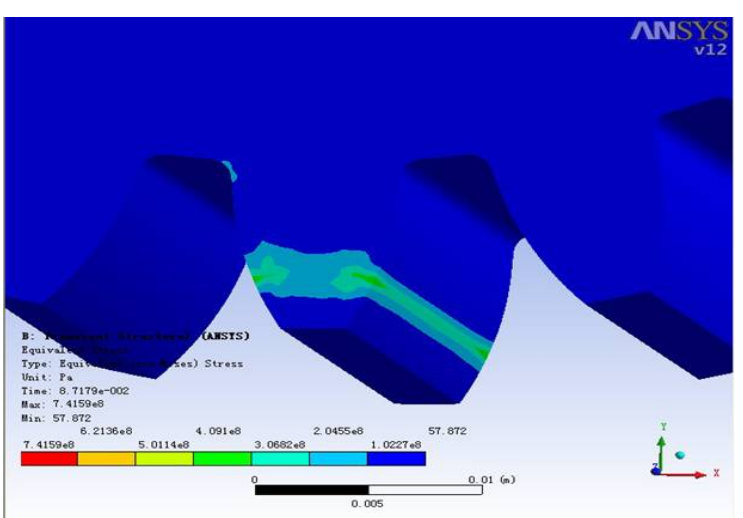

(d) $\mathrm{T}=0.12 \mathrm{~s}$ Gear stress contour

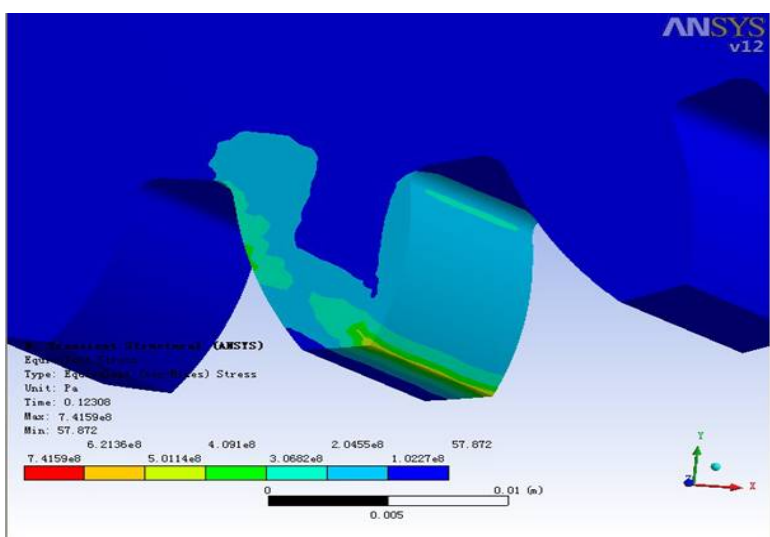

Fig. (6). Gear stress contour 
(a) $\mathrm{T}=0.03 \mathrm{~s}$ Rack stress contour

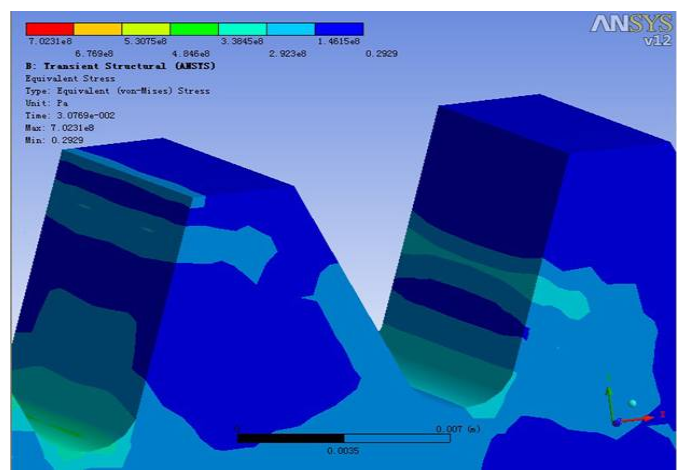

(b) $\mathrm{T}=0.05 \mathrm{~s}$ Rack stress contour

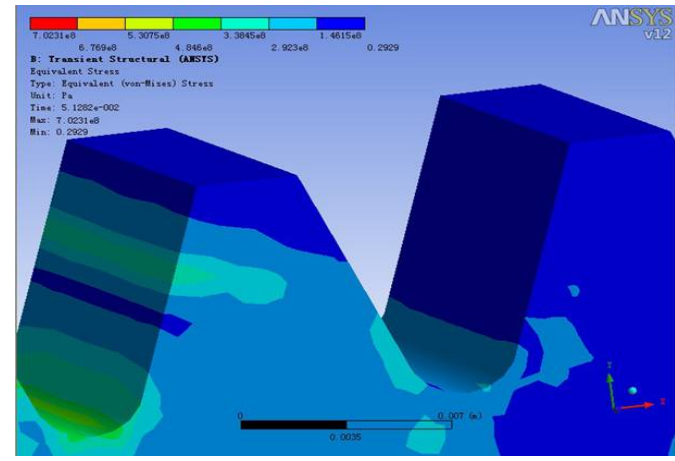

(c) $\mathrm{T}=0.08 \mathrm{~s}$ Rack stress contour

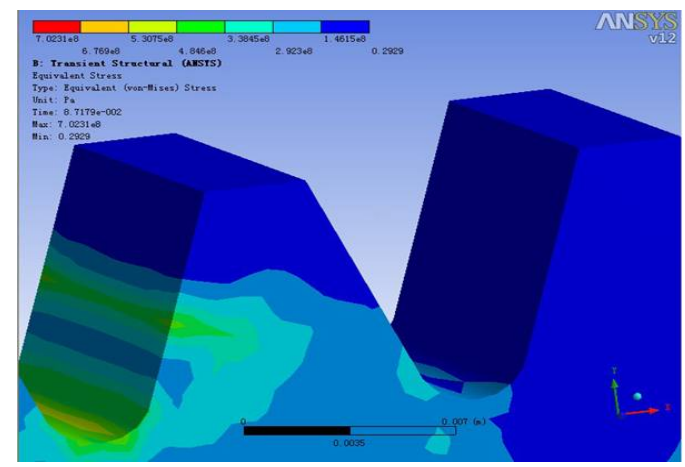

(d) $\mathrm{T}=0.12 \mathrm{~s}$ Rack stress contour

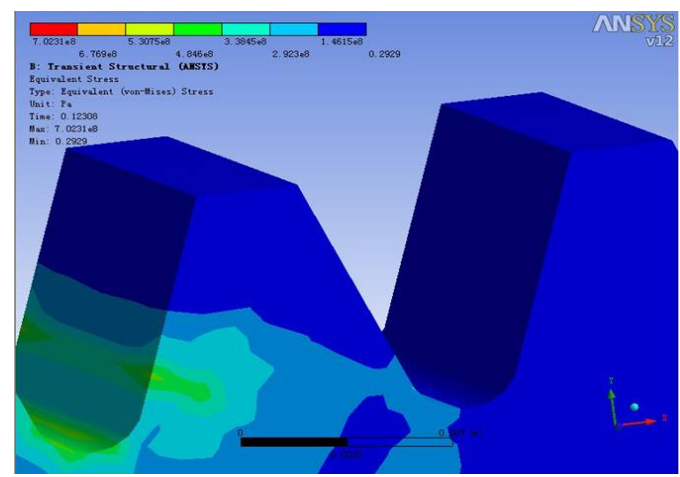

Fig. (7). Rack stress contour.
1) According to the modal analysis, the natural frequencies of the gear and rack transmission system are identified and the gear meshing frequency is $16 \mathrm{~Hz}$ at the speed of $0.65 \mathrm{r} / \mathrm{s}$ by calculation, which is far less than the lowest natural frequency. It can also avoid the resonance frequency. In order to improve production efficiency, the gear speed can be improved.

2) According to the transient dynamic analysis, the equivalent stress distribution at different time in the gear and rack meshing contact process is obtained, which indicates that in the situation of top speed of $4.08 \mathrm{rad} / \mathrm{s}$ of the gear, the maximum equivalent stress of gear is $741.59 \mathrm{MPa}$, less than the tensile strength $860 \mathrm{MPa}$ and the maximum stress of rack is 702.31MPa, less than the bending strength $815.28 \mathrm{MPa}$ of the rack, which shows that the strength is reliable.

3) The maximum equivalent stress of the gear and rack occurs in the gear and rack out-meshing contact point, and only in this point, because there is local high stress in the addendum line. This is why gear tooth is patched on the top to avoid the condition of local high stress in engineering.

4) The contact stress and bending stress of the gear and rack system gained by FEM can avoid the problem of time-consuming and inexact calculation result by traditional Hertz Theory.

\section{CONFLICT OF INTEREST}

The authors confirm that this article content has no conflict of interest.

\section{ACKNOWLEDGEMENTS}

Declared none.

\section{REFERENCES}

[1] X.Q. Zhang, D.G. He, and R. Zheng, "Contact stress analysis of gear and rack," Journal of Mechanical Transmission, vol. 7, pp. 30-32, 2011

[2] Y.X. Li, Z. Wang, and M.X. Wang, "Discussion of large modulus gear- rack bending fatigue strength," Journal of Mechanical Transmission, vol. 10, pp. 1-3, 2012.

[3] Q.J. Xiao, H.G. Jia, and X.F. Han, "Study on dynamic contact of gear and rack by considering elastic and plastic properties of material," Coal Mine Machinery, vol. 1, pp. 86-89, 2013.

[4] J.J. Wang, and R.F. Li, "The theoretical system of the gear vibration theory," China Mechanical Engineering, vol. 9, pp. 55$58,1998$.

[5] L. Zhou, S.F. Zheng, and X.M. Lian, "Modeling and research on torsional vibration of transmission system under speeding-up condition," Journal of Vibration Engineering, vol. 12, pp. 601605, 2010.

[6] X.Y. Xu, C.C. Zhu, and X.R. Zhang, "Experimental modal analysis of heavy duty marine gearbox," Journal of Vibration and Shock, vol. 7, pp. 266-270, 2011.

[7] F. Sun, "Modal analysis and research of gear with fewer teeth based on ANSYS," Machinery Design \& Manufacture, vol. 5 , pp. 119-121, 2011. 
[8] K. Chen, Y. Luan, and X.H. Deng, "Transient dynamics analysis for uniform engaging process of MC nylon helical gear," Machinery Design \& Manufacture, vol. 3, pp. 110-112, 2012.
[9] Y. Ge, and Y.E. Yang, "Transient response of gear based on FEA," Manufacturing Automation, vol. 9, pp. 110-115, 2010.

(C) Yanjun et al.; Licensee Bentham Open.

This is an open access article licensed under the terms of the Creative Commons Attribution Non-Commercial License (http://creativecommons.org/licenses/by-nc/3.0/) which permits unrestricted, non-commercial use, distribution and reproduction in any medium, provided the work is properly cited. 